\title{
Workload Distribution Within an Extensive Case Pedagogy: A Competitive Bidding Strategy
}

\author{
David Malone, (Email: malone@ba.ttu.edu), Texas Tech University
}

\begin{abstract}
This paper presents a bidding strategy that may be incorporated into case-intensive courses. The purpose of the bidding process is to equitably distribute credit when students are assigned cases of differing degrees of difficulty. The paper also collects data to help answer a basic research question regarding this device: Is there evidence of bounded rationality among students in executing their bidding strategies? While there does appear to be evidence of some bounded rationality, the bidding mechanism appears to distribute workload and credit rationally.
\end{abstract}

Introduction

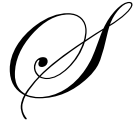
ince the Accounting Education Change Commission (AECC) began proffering its recommendations in 1990 [AECC, 1990], accounting educators have been re-examining long held traditions in the structure of the accounting curriculum, content of accounting courses, and pedagogies employed. Accounting academics have been asked to consider ways of making our students more capable in a wide range of "softer" skills, such as oral and written communications, working in groups, critical thinking, and working under pressure [Albrecht, et al, 1994].

The case method is generally recognized as a pedagogical technique with promise to enhance a variety of skills in students, including their ability to work in groups and to solve complex, real-world problems. The case method offers several specific strengths toward larger learning objectives in a classroom setting, including development of higher order reasoning skills, including reasoning and judgment, allowing the opportunity to learn by doing, bringing softer and subjective skills into play, and offering realism in the learning environment [AAA, 1987; AECC, 1990; Campbell and Lewis, 1991; Lindquist, 1995; Sawyer, et al., 2000; Hackney et al., 2003; Ballantine and Larres, 2004]. Further, assigning students the task of presenting case solutions in class allows students to develop confidence in their communication skills, both interpersonal and public [Knechel, 1992.] Greenstein and Hall [1996] argue that through the use of cases, student cognitive skills are pushed up from the knowledge and comprehension levels of Bloom's taxonomy into the realms of application, analysis and synthesis.

A problem arises, however, when multiple cases with varying degrees of difficulty are used in one course. Students assigned more difficult cases will be required to expend more effort on developing their solution than those assigned less difficult ones. One way of resolving this problem may be to assign weights to cases, so that student grades can be adjusted according to the level of effort required to complete a case assignment. Better still may be to allow students to self-select into cases according to their own sets of preferences for potential reward/effort relationships. 
The purpose of this paper is to describe a method of assigning cases using a bidding process that was successfully employed in three sections of a case-intensive MBA accounting course. In the bidding process that is described herein, students are placed in a competitive bidding game whereby cases are bid on the basis of lowest credit bid for a given case. Specifically, students could receive a maximum of $100 \%$ of the credit available only if they were to bid 1 for a given case (which would reduce the likelihood of winning that case, since the maximum bid is 1.) If a winning bid (i.e., the lowest bid) were 0.8 , then that team could receive a maximum of $80 \%$ of the credit afforded that assignment, and that only if they were to complete the assignment with a perfect score or evaluation.

Finally, on a larger note, this paper serves to add to the literature on the use of case studies in accounting education. Libby [1991] and Stout [1996] observed that a significant impediment to the use of cases is a lack of empirical evidence about the effects of using cases in an accounting course. The study presented here adds to the knowledge base of what benefits and problems may be associated with the case method as a pedagogical choice and presents empirical evidence to support those points.

\section{Course Environment}

The course in which this method was implemented was a four semester hour course covering introductory financial and managerial accounting. It was offered at the graduate level for MBA students and intended for students with little or no exposure to accounting. The experiment lasted two semesters and covered three sections of the course. The average enrollment was 35 students per section. Twentyone Harvard Business School cases were used each semester.

A variety of benefits accrue from requiring student preparation and presentation of cases. Adler et al. [2004] argued that self-directed learning that emerges in student presentation of cases is more consistent with the learning objectives intended in the case method, by comparison to a teacher-led case pedagogy. Students assigned to the case, therefore, were asked to lead the in-class presentation of the case. In general, teams of two students were assigned one case each. In two of the sections, the professor presented the first case to provide an example of expectations held out for the presentations. Enrollment in the third class was 47 students, requiring that a team be assigned to the first case, and that five teams be assigned three students instead of two. As will be explained later, information as to case difficulty was provided in that class, and teams of three assigned to the five most difficult.

The case presentation counted for five percent of a student's grade. Assessment of the presentation was made of the team, rather than of the individual team members. While a team was not required to submit a written analysis of their case, every team employed a PowerPoint ${ }^{\circledR}$ presentation that contained thorough documentation of their solutions.

Each student in the course, whether presenting or not, was expected to be thoroughly prepared for each case. Preparedness was monitored through a series of quizzes that were administered on a random basis. Participation was observed and graded to provide additional incentives for case preparation among class members.

\section{Bidding Process}

The purpose of the bidding process was to implement a system whereby students themselves play a role in distributing credit for the cases to which they are assigned. To accomplish this, students, on the first day of class were given a list of cases, each contained in their text, in the form of a bidding sheet. In sections 1 and 2 of the course (i.e., the first semester,) no information was provided as to the degree of 
difficulty of the cases (as there was none at that point.) In section 3, degree of difficulty ratings, collected from the first semester, were provided. This information, along with a space for team bids, was provided in the form of a bidding sheet (see Appendix.)

On that first class day, students were asked to form teams of two through self-selection. Teams would then be expected to participate in the bidding process, prepare and present a formal presentation of the case to the class, and share evaluation credit assigned to the team by their peers. Teams were chosen, in part, because there were too few cases to distribute among all class members individually. The benefits of teams, however, extend well beyond that. Forman and Rymer [1999] suggest that team presentations under the case method foster negotiation and debating skills among students within groups, describing the process as a democratic one. Of course, sharing the workload also helped improve the quality of the presentations.

The teams were asked to review the cases listed on the bidding sheet and develop bids for each, to be turned in during the following class period. There was also a general discussion about possible strategies and implications of those strategies. For example, one student asked why anyone would bid less than one for a case, why would one accept less than the possibility of full credit? In response, another student observed that were each team to follow such a strategy, the easiest of all cases could be won with a bid of 0.99. In an environment where time is a precious commodity, and where an easier case assignment frees up time for other activities (time to study other material, for example,) a team should be willing to sacrifice part of their potential credit not just for easier cases. When asked about their bidding strategies, students listed several reasons for bidding the way they did. Reasons, other than difficulty of case, that emerged for bidding aggressively included:

- Timing in the semester - some students wanted to get their cases over quickly, so bid lowest on early cases. Other students wanted more time and bid highest on earlier cases. Several students indicated prior obligations on certain dates, bidding the maximum for the cases listed for those dates to insure against winning those cases. Students also suggested bidding strategies to avoid periods in the semester when tests were scheduled.

- Interest in the case - students mentioned interest in several of the real cases, including Delta/Singapore, Nordstrom's, and Reynolds Tobacco. An avid baseball fan convinced his team to bid aggressively on the Kansas City Zephyrs case.

- Leveraging their strengths - students coming from an undergraduate background in finance, for example, sought out Laurinburg Precision Engineering - a case emphasizing time value of money in an investment capital decision. ${ }^{1}$

Of course, there was evidence of bounded rationality in the bidding process. While many students formed a cogent strategy in their bidding, others displayed a limited ability to process the nature of the game. Systematic evidence exists supporting a bounded rationality argument and will be presented later.

As mentioned above, students bid a percentage of the score they were willing to accept for a case. In the third section, students were given degree of difficulty information to assist them in forming a set of bidding preferences. At the beginning of the second class period, each team turned in a bidding sheet

$1 \quad$ Ballantine and Larres [2004] found no difference in attitudes toward the case method between individuals with work experience and those without; however, several subjects of the current study clearly leveraged their strengths in the bidding process. In some cases, the source of those strengths was their undergraduate education, but in others it was knowledge acquired through work experience. 
with their bids. Assignments were made for each case taking the lowest bid for each case in succession, with the winning team then dropping out of the bidding.

Occasionally, a tie would occur between teams. In those instances, the tying teams were asked to re-bid, until a definitive winner emerged. Invariably, the tying teams would look to one another in an effort to determine what the other team's strategy might be. A few teams even asked what the other team intended to bid - to no avail, of course. Perhaps the best anecdote of resolving ties was one team, upon notification of a tie, turned to the other team and offered $\$ 10$ to give up the case. The offer was accepted.

\section{Bounded Rationality in Bidding}

From the pedagogy described above, a research question presented itself: Was there evidence of bounded rationality among students in executing bidding strategies?

Anecdotally, one team won the Colgate-Palmolive case with a bid that serves to illustrate this concern. On that team, a student convinced her partner to bid 0.1 for Colgate-Palmolive. Even though the weighting system had been thoroughly explained, this student still believed that if they could be innovative and clever in their presentation, high evaluations would make up for a low bid. That by bidding 0.1 on the case meant that the maximum credit they could now receive was 0.5 of the five points allocated to the case presentation, and that only with a perfect evaluation, escaped her. Most problematic was that she had been able to convince her partner of the bidding strategy. Perhaps as even more evidence of bounded rationality was that they put a significant effort into the case, even though they received virtually no credit for it (except for the recognition by the professor that they had moved beyond mere grade considerations, and fulfilled their responsibility to the class.)

Of course, one may argue that in an MBA class, capturing a student's incapacity to interpret a game (in the strictest sense) and allowing it to adversely affect his or her grade may be a good thing. Arguably, it is difficult to know exactly where that notion might fit in the syllabus (e.g., "If you exhibit irrational thinking, you will earn a lower grade.”)

The purpose of the bidding process is to implement a device that will provide distributive equity in the assignment of student caseload. The presence of bounded rationality limits the effectiveness of that process. One way of answering the larger question of bounded rationality is whether the outcomes are consistent with a priori expectations. Presumably, students bid high on cases in order to make it possible to acquire higher net credit on their assignment (or, possibly, to avoid cases they do not want to present.) If there were no difference expected between net credit earned among students who win with high bids and those with low bids, then a rational expectation is that students would bid at a consistently low level, and that cases would be assigned on more of a random basis. Of course, students bidding high would hope to acquire more credit by working harder on a more difficult case. If net credit for students working on difficult cases is the same as those working on less difficult cases, those bidding high for the purpose of acquiring higher credit would not be following a rational strategy, ex post. The hypothesis suggested, in alternate form, is:

\section{$\mathrm{H1}_{\mathrm{a}}$ : Net credit earned through peer evaluations is positively related to case difficulty.}

In each of the preceding hypotheses, rejection of the null would suggest limitations of the pedagogy discussed in this paper, whether from self-interested behavior or qualitative shortcomings in the peer evaluations. In this instance, however, a positive relationship between net credit and case difficulty would reinforce the reward structure designed into this system, and represent a desirable outcome. 
Referring to Exhibit 1, Panel 1, data gathered over these two semesters does suggest a strong statistical relationship, accompanied by a relatively high adjusted R-square and a positive coefficient. The study concludes, therefore, that there is a reinforcing incentive structure in place that rewards the extra effort necessary to complete a more difficult case.

\section{Exhibit 1 \\ Statistical Results for Hypotheses}

Panel 1: Net Case Score $=f($ Case Difficulty $)$

$\begin{array}{llllll}\text { R-square } & 0.2492 & & & & \\ \text { Adj R-square } & 0.2425 & & & & \\ \text { Source } & \text { DF } & \text { SS } & \text { MS } & \text { F } & \text { Pr }>\text { F } \\ & & & & & \\ \text { Model } & 1 & 13.69 & 13.69 & 36.85 & 0.0000 \\ \text { Error } & 111 & 41.24 & .372 & & \\ \text { Total } & 112 & 54.93 & & & \end{array}$

Panel 2: Student Bids with Difficulty Information $=f$ (Student Bids without Difficulty Information)

(Paired $t$-test for Sample Means)

$\begin{array}{lcc}\text { Student Bids without } & \begin{array}{c}\text { Student Bids with } \\ \text { Difficulty } \\ \text { Information } \\ \text { Mean }\end{array} & \begin{array}{c}\text { Difficulty Information } \\ \text { Variance }\end{array} \\ \begin{array}{l}\text { Observations } \\ \text { Degrees of }\end{array} & 0.0837 & 0.7405 \\ \text { Freedom } & 19 & 0.0133 \\ t & 18 & 19 \\ \mathrm{P} t<T & & \\ & 6.826 & \end{array}$

In advance of submitting bids, student assessment of case difficulty may be a source of bounded rationality. In the first semester (sections 1 and 2) of administering this method, students were not provided information on relative case difficulty. In the second semester (section 3,) mean assessments of degree of difficulty, assigned by students in the first semester, were given to students upon which they based bidding decisions. The question that presents itself is whether students in the first semester accurately assessed degree of difficulty.

Absent any authoritative statement of case difficulty (by the authors, for example,) measurements of how accurately students assessed degree of difficulty prior to bidding proved difficult. Part of the problem was bidding strategies were not driven by difficulty alone. As mentioned earlier, timing in the 
semester, personal interest in the case, and other elements were factored into student bids. The method adopted here assumes factors affecting bidding other than difficulty were approximately the same between first and second semesters. Therefore, given that students in the second semester were given information from students in the first semester about degree of difficulty, and assuming early assessments by first semester students were accurate, average bids for each case would be the same that semester as they were in the second semester. Thus:

\section{H2 ${ }_{\mathrm{a}}$ : Student bids for cases in the first semester are positively correlated to student bids for cases in the second semester.}

Panel 2 in Exhibit 1 shows that mean bids in the first semester (no information about degree of difficulty) were higher and more narrowly distributed than those in the second semester. This suggests that students in the first semester were operating under greater uncertainty, so tended to bid higher on cases. In the second semester, however, with information that identified easier cases, students were willing to be more aggressive in their bidding in order to win those cases.

While bidding in the first semester seems to have been less aggressive due to uncertainty about difficulty, the question remains of whether students correctly ordered their bids, even in the presence of that uncertainty. While students may not be certain about how difficult a case is, they may still possess adequate information to assign a generally correct order to those cases by level of difficulty.

\section{H3 : Rank order of bids in the first semester was different than that in the second semester.}

This hypothesis was tested using Spearman's Rank Order Correlation, which produced an $r$ of 0.3429 and a p-value of 0.1389 . This result, therefore, fails to support the argument that ranks were the same in both semesters, and suggests that students rank ordered the cases differently than had they ordered the cases strictly on an informed basis of degree of difficulty. As pointed out earlier, there were more factors involved in bidding than just degree of difficulty; however, ceteris paribus, this data suggests some degree of bounded rationality.

\section{Summary, Conclusions and Recommendations}

The purpose of this paper has been to describe an equitable method of distributing workload in an environment where students are responsible for the preparation and presentation of cases of unequal levels of difficulty. The method described required students to formulate a strategy for competitively bidding on twenty-one cases to be presented by students throughout the semester. By using a bidding process, students themselves could decide whether they were willing to take on more difficult and timeconsuming cases for more credit, or be satisfied with easier, less time-consuming cases that yielded lower net credit in the grading mechanism.

Data were gathered to assess the effectiveness and ex post equity in this method of distributing case loads. While there was evidence of bounded rationality, outcomes from the distribution of cases were shown to be consistent with objectives of the method. Stated specifically:

1. Higher bids won more difficult cases.

2. More difficult cases yielded more credit in the grading process.

At the end of each semester, students who adopted a bidding strategy that would yield a more difficult case were rewarded with higher net peer evaluations for those cases, either through higher degree of difficulty adjustments or higher peer evaluations in exchange for their willingness to take on more 
difficult cases. In the first semester, in particular, there seemed to be little correlation between degrees of difficulty and winning bid values, yet there was still a net reward to the teams who were assigned more difficult cases. While this effect seemed to persist through both semesters, it compensated for the bounded rationality that apparently existed in the first semester when there was no guidance provided in level of difficulty among the cases. Perhaps, then, the first recommendation may be to provide students with information on case difficulty prior to bidding. This effect may also have been the product of peer evaluations used in each of these courses. Whether evaluations by the professor would have resulted in scores less influenced by degree of difficulty is unclear.

\section{References}

Albrecht, W. S., Clark, D. C., Smith, J. M., Stocks, K. D., and Woodfield, L. W., (1994). An accounting curriculum for the next century. Issues in Accounting Education 9(2) 401-425.

Accounting Education Change Commission, (1990). Objectives of education for accountants: Position statement No. 1. Issues in Accounting Education 5(2) 307-312.

Adler, R. W., Whiting, R. H. and Wynn-Williams, K., (2004). Student-led and teacher-led case presentations: Empirical evidence about learning styles in an accounting course. Accounting Education 13(2) 213-229.

American Accounting Association, (1986). Future accounting education: Preparing for the expanding profession. Issues in Accounting Education 1(1) 168-195.

Ballantine, J. A. and Larres, P. M., (2004). A critical analysis of students' perceptions of the usefulness of the case study method in an advanced management accounting module: the impact of relevant work experience. Accounting Education 13(2) 171-189.

Campbell, J. E. and Lewis, W. F., (1991). Using cases in accounting classes. Issues in Accounting Education 6(2) 276-283.

Forman, J. and Rymer, J., (1999). The genre system of the Harvard case method. Journal of Business and Technical Communication 13(4) 373-400.

Greenstein, M. M. and Hall, J. A., (1996). Using student-generated cases to teach accounting information systems. Journal of Accounting Education 14(4) 493-514.

Hackney, R., McMaster, T. and Harris, A., (2003). Using cases as a teaching tool in IS education. Journal of Information Systems Education 14(3) 229-234.

Kilpatrick, D. J., Linville, M., and Stout, D. E., (2001). Procedural justice and the development and use of peer evaluations in business and accounting classes. Journal of Accounting Education 19(4) 225-246.

Knechel, W. R., (1992). Using the case method in accounting instruction. Issues in Accounting Education 7(2) 205-217. 
Libby, P. A., (1991). Barriers to using cases in accounting education. Issues in Accounting Education 6(2) 193-213.

Lindquist, T. M., (1995). Traditional versus contemporary goals and methods in accounting education: Bridging the gap with cooperative learning. Journal of Education for Business 70(5) 278-284.

Sawyer, A. J., Tomlinson, S. R. and Maples, A. J., (2000). Developing essential skills through case study scenarios. Journal of Accounting Education 18(3) 257-282.

Stout, D. E., (1996). Experiential evidence and recommendations regarding case-based teaching in undergraduate cost accounting. Journal of Accounting Education 14(3) 293-317. 


\section{Appendix}

\section{Student Bidding Sheet}

\begin{tabular}{|c|c|c|}
\hline Case & $\begin{array}{c}\text { Difficulty } \\
\text { Rating }\end{array}$ & Bid \\
\hline \multicolumn{3}{|l|}{ Chemalite, Inc. } \\
\hline Colgate-Palmolive Company & 71.6 & \\
\hline LIFO or FIFO? That is the Question & 73 & \\
\hline R. J. Reynolds Tobacco Company & 71 & \\
\hline The Intel Pentium Chip Controversy (A) & 77.6 & \\
\hline Depreciation at Delta Air Lines and Singapore Airlines (A) and (B) & 84.3 & \\
\hline Kansas City Zephyrs Baseball Club, Inc. & 80 & \\
\hline Laurinburg Precision Engineering & 73.1 & \\
\hline Accounting for Frequent Fliers & 81.8 & \\
\hline FMC Corporation & 76.4 & \\
\hline Statements of Cash Flows: Three Examples & 78.4 & \\
\hline Crystal Meadows of Tahoe, Inc. & 86.6 & \\
\hline Precision Worldwide, Inc. & 76.7 & \\
\hline Lilly Tissages, S.A. & 79.5 & \\
\hline Prestige Telephone Company & 81.4 & \\
\hline Hilton Manufacturing Company & 80.4 & \\
\hline Seligram, Inc.: Electronic Testing Operations & 86 & \\
\hline Destin Brass Products Co. & 82.8 & \\
\hline Nordstrom: Dissension in the Ranks (A) & 75.9 & \\
\hline Western Chemical Corporation: Divisional Performance Measurement & 83.9 & \\
\hline Chadwick, Inc.: The Balanced Scorecard (Abridged) & 74.6 & \\
\hline
\end{tabular}




\section{Notes}


